\title{
Factores socioeconómicos y contextuales que determinan la actividad reproductiva de las adolescentes en Colombia ${ }^{1}$
}

\author{
Carmen Elisa Flórez ${ }^{2}$
}

Forma de citar

Flórez CE. Factores socioeconómicos y contextuales que determinan la actividad reproductiva de las adolescentes en Colombia. Rev Panam Salud Publica. 2005;18(6):388-402.

RESUMEN Objetivo. Contribuir a un mejor entendimiento de la problemática del embarazo en las adolescentes y de sus factores determinantes, próximos y socioeconómicos, en dos contextos culturalmente diferentes, las ciudades de Cali y Santa Fe de Bogotá, en Colombia.

Método. De carácter longitudinal, el estudio combina métodos de investigación cuantitativa y cualitativa. Se basa en la encuesta retrospectiva, cuantitativa y cualitativa de salud de los adolescentes de 2003. La encuesta cuantitativa tuvo una muestra de 1100 adolescentes representativas de cada estrato socioeconómico. Para el análisis de los factores determinantes se utilizaron modelos de riesgo proporcional de tiempo discreto. Para el estudio cualitativo se efectuaron 72 entrevistas a profundidad y cuatro grupos focales. Asimismo, se identificaron las categorías que surgían de pautas y recurrencias en los datos, para generar patrones socioculturales por sexo, estrato y ciudad.

Resultados. Los patrones de actividad sexual, unión y maternidad difieren considerablemente entre estratos en las dos ciudades. Las adolescentes del estrato bajo inician las relaciones sexuales, se unen a compañeros y son madres con mucha mayor antelación e intensidad que las de estratos más altos. El principal factor determinante del comportamiento reproductivo de las adolescentes es el conjunto de influencias contextuales y socioeconómicas del hogar, principalmente el contexto familiar (ambiente y supervisión) y el clima educativo.

Conclusiones. Resulta evidente el escaso impacto que ha tenido la educación sexual que se imparte en las escuelas, desde 1993, en el comportamiento reproductivo de las adolescentes.

Palabras clave Adolescente, embarazo en adolescencia, conducta sexual, Colombia.

1 Este artículo resume algunos resultados del estudio "Fecundidad adolescente en Colombia: incidencia, tendencias y determinantes", realizado en la Universidad de Los Andes por un grupo de investigación conformado por Carmen Elisa Flórez y Victoria Soto, del Centro de Estudios sobre Desarrollo Económico (CEDE), y por Elvia Vargas, Juanita Henao y Constanza González, del Departamento de Psicología. El estudio se desarrolló con el apoyo financiero del Programa Nacional de Ciencia y Tecnología de la Salud de COLCIENCIAS y del Fondo de Población de las Naciones Unidas.

2 Centro de Estudios sobre Desarrollo Económico (CEDE), Facultad de Economía, Universidad de Los Andes, Santa Fe de Bogotá, Colombia. Toda correspondencia deberá dirigirse a: Carmen Elisa
El inicio de la fecundidad en la adolescencia es un fenómeno que tiene importantes implicaciones en los ámbitos personal y social, más aún cuando se produce a edades tempranas en este período. Desde el punto de vista indi-

Florez, Cra. 1E No. 18 A 10, Santa Fe de Bogotá, Colombia. Tel: (57) (1) 339-4949/99, ext. 2410. Fax: (57) (1) 332-4492. Correo electrónico cflorez@ uniandes.edu.co vidual, las consecuencias del embarazo en la adolescencia son amplias y en general de carácter negativo, tanto para el niño como para la madre, en particular cuando se produce al principio de la adolescencia, antes de haberse constituido una unión estable, sea esta de carácter libre o formal. Los riesgos en términos de salud, deserción escolar, pérdida de futuras oportunidades económicas y dificultades emociona- 
les, físicas y financieras, son algunas de las consecuencias para la joven madre. En general, la fecundidad alta en la adolescencia, ante todo en la adolescencia temprana, se relaciona claramente con el truncamiento de la trayectoria educativa y con limitaciones para la participación laboral futura. En lo que respecta al niño, las consecuencias recaen en la salud -mayores riegos de morbilidad y mortalidad durante el período neonatal-, en vista del escaso desarrollo físico y emocional de la mujer. En lo que toca a la sociedad global, el crecimiento de la población se acelera cuando las mujeres tienen su primer hijo antes de los 20 años, dada la reducción del tiempo de reemplazo entre generaciones (1).

En el caso de Colombia, las Encuestas de Demografía y Salud indican que la incidencia de la fecundidad en adolescentes ha venido aumentando, junto a una tasa creciente de embarazos y nacimientos prematrimoniales y un aumento significativo del inicio temprano de la actividad sexual $(2,3)$. No se esperaba en Colombia esa tendencia al aumento de la fecundidad en adolescentes, vistos ciertos cambios positivos en algunos de los factores determinantes socioeconómicos en los ámbitos individual y contextual. Así, se ha apreciado una mayor permanencia en el sistema educativo, aumento de la escolaridad y una mayor participación laboral (en particular de la mujer), mayor disponibilidad y acceso a métodos de planificación familiar, mayor grado de urbanización y cambios favorables en los conceptos $y$ valores acerca de la maternidad y la familia $(4,5)$. Asimismo, durante el último decenio se ha avanzado considerablemente también, tanto en el ámbito internacional como en el nacional, en aspectos relacionados con la salud y con los derechos sexuales y reproductivos, que deberían contribuir a disminuir la fecundidad en adolescentes. Así, ya en 1994 se promulgaba en Colombia la Ley de Educación Sexual (Ley 115 de 1994), que hace obligatorio cumplir con la educación sexual a través de proyectos pedagógicos desarrollados de acuerdo con un plan de estudios (6), y el gobierno colombiano definió en 1998 los lineamientos para la política de salud sexual y reproductiva, incorporando el derecho a la educación sexual y reproductiva desde la infancia, así como a servicios de salud sexual y reproductiva integral (7).

Frente a estos cambios positivos, ¿cómo entender el aumento de la fecundidad en adolescentes? ¿Cuáles son los factores que explican su tendencia ascendente? Este es el tipo de preguntas que se pretende abordar aquí en el caso específico de Colombia. La intención del estudio es avanzar en el conocimiento de la problemática del embarazo en adolescentes en Colombia y de sus factores determinantes, próximos y socioeconómicos, con profundización en dos contextos culturalmente diferentes: Cali y Santa Fe de Bogotá. Estas dos ciudades, las dos principales del país, no solo difieren en el orden cultural, sino que muestran comportamientos opuestos en los niveles y tendencias de la fecundidad en adolescentes. Por una parte, Cali es, entre las grandes ciudades, la de mayor fecundidad en adolescentes y, en los últimos cinco años ha mostrado un aumento importante en este aspecto. Por otra, Bogotá es la ciudad principal con la menor fecundidad en adolescentes y muestra un descenso de esta variable (3).

El artículo está organizado en tres secciones. En la primera, que presenta la metodología, se exponen el enfoque y el marco analítico, las fuentes de información y el modelo estadístico utilizado. La segunda analiza los factores determinantes socioeconómicos y contextuales de dos sucesos en la vida de las adolescentes: el inicio de las relaciones sexuales y el primer embarazo. Por último, en la tercera sección se ofrecen algunas conclusiones.

\section{MÉTODO}

\section{Diseño del estudio}

El estudio, de carácter longitudinal y con un enfoque de historia de vida, combina métodos de investigación cuantitativa y cualitativa. El enfoque de historia de vida ${ }^{3}$ permite analizar la aparición de los diferentes sucesos y su relación con los otros aspectos de la vida en el momento en que se producen. A diferencia de los estudios de corte transversal, el enfoque de historia de vida (retrospectiva) permite relacionar las diferentes transiciones a lo largo de la vida en el momento en que se producen. La decisión de tener un hijo o de casarse o unirse depende de características individuales y circunstancias que están presentes cuando se toma la decisión y no de las que están presentes en el momento de la encuesta. La combinación de métodos de investigación cuantitativa y cualitativa permite complementar las perspectivas y los análisis del problema.

\section{Marco de análisis}

El marco conceptual general necesario para analizar los muy diversos mecanismos y vías que constituyen las asociaciones entre fecundidad y sus factores determinantes se basa en la extensa literatura que existe sobre el tema. Partiremos aquí del marco conceptual expuesto por Simmons (8), el cual recoge ampliamente los planteamientos propuestos en la literatura (figura 1). Las condiciones socioeconómicas y contextuales afectan al nivel y al patrón etario de la fecundidad a través de los factores determinantes próximos. Davis y Blake (11) identificaron tres grupos de estos factores, que tercian entre las normas y la estructura social de una sociedad y su nivel de fecundidad: los relacionados con la exposición al riesgo de embarazo, con la concepción y con la gestación. Desarrollos ulteriores han incluido la infertilidad posparto y se han concentrado en los factores que son determinantes importantes de la fecundidad y que, al mismo tiempo, varían entre grupos poblacionales, a saber: inicio de las relaciones sexuales, matrimonio o unión;

\footnotetext{
El enfoque de la historia de vida pone de relieve que las transiciones son "creadas, reconocidas y compartidas socialmente" (9) y reconoce que los cambios ocurren en múltiples dimensiones a lo largo del tiempo (10).
} 
FIGURA 1. Marco conceptual sobre los factores determinantes de la fecundidad en adolescentes (adaptado de Simmons [8])

\begin{tabular}{|c|c|c|c|}
\hline $\begin{array}{l}\text { Políticas y acciones } \\
\text { del gobierno }\end{array}$ & $\begin{array}{c}\text { Factores determinantes } \\
\text { socioeconómicos y contextuales }\end{array}$ & $\begin{array}{l}\text { Factores determi- } \\
\text { nantes próximos }\end{array}$ & $\begin{array}{l}\text { Nivel y patrón } \\
\text { de fecundidad }\end{array}$ \\
\hline & Nivel hogar e individual: & \multirow{6}{*}{\begin{tabular}{|l|} 
- Sexo pre- \\
matrimonial \\
- Matrimonio o \\
unión libre \\
- Planificación \\
familiar \\
- Aborto \\
\end{tabular}} & \multirow{6}{*}{$\rightarrow$ Fecundidad } \\
\hline \multirow{3}{*}{\begin{tabular}{|l|} 
Políticas y \\
programas de \\
salud: provisión \\
de servicios de \\
salud, educación \\
sexual y \\
planificación \\
familiar \\
\end{tabular}} & $\rightarrow \begin{array}{l}\text { Características del hogar: } \\
\text { activos, ingreso, estrato } \\
\text { socioeconómico, jefatura } \\
\text { femenina, estructura del } \\
\text { hogar, etc. }\end{array}$ & & \\
\hline & $\left\{\begin{array}{l}\text { Características del individuo: } \\
\text { educación, empleo, edad, } \\
\text { etc. }\end{array}\right.$ & & \\
\hline & Nivel contextual: & & \\
\hline \multirow[t]{2}{*}{$\begin{array}{l}\text { Otras políticas y } \\
\text { programas } \\
\text { sectoriales: oferta } \\
\text { en sectores } \\
\text { relacionados } \\
\text { (educación, } \\
\text { empleo) }\end{array}$} & $\begin{array}{l}\text { Factores de la comunidad: } \\
\text { estrato socioeconómico de la } \\
\text { mujer, nivel educativo, empleo } \\
\text { femenino, uso de planificación } \\
\text { familiar, edad promedio a la } \\
\text { unión, etc. }\end{array}$ & & \\
\hline & normas sociales, significados & & \\
\hline
\end{tabular}

anticoncepción; aborto, e infertilidad posparto (12). Es de esperar que el efecto de la exposición al riesgo de embarazo sea menos importante cuanto mayor sea la aceptación y el uso de métodos de planificación familiar. De igual modo, cuanto mayor sea la exposición al riesgo de embarazo y menor el acceso a métodos de planificación familiar, tanto mayor será la importancia del aborto. Sin embargo, Guzmán, Márquez y Contreras (13) afirman que en la mayor parte de los países latinoamericanos es más probable que el embarazo prematrimonial culmine en matrimonio que en aborto.

De acuerdo con el marco conceptual, se considera que tres tipos de factores ejercen influencia directa e indirecta en la fecundidad por medio de los determinantes próximos. Se parte de las políticas y programas gubernamentales en los sectores de salud y otros relacionados (educación, empleo), mediante los cuales se organiza la oferta de servicios de salud, de planificación familiar y de los bienes de otros sectores (educación, empleo) que inciden de forma directa o indirecta en la fecundidad. En segundo lugar están los factores socioeconómicos globales o el contexto social en que vive el adolescente, incluido el discurso social sobre el matrimonio, la actividad sexual prematrimonial, la pareja, el amor y la familia, entre otros. En tercer lugar están los factores socioeconómicos particulares, o características individuales de la adolescente y del hogar en que reside.

El marco analítico subraya la fuerte influencia que ejerce el contexto sociocultural en la fecundidad y sus factores determinantes próximos. Los significados que se adscriben a la masculinidad y a la feminidad pueden ayudar a definir la identidad del adolescente $y$, con ello, influir en su participación en la dinámica de los encuentros sexuales. Mediante la transmisión de significados y sentidos subjetivos acerca del comportamiento sexual de hombres y mujeres, el contexto cultural puede influir también en las decisiones respecto a si iniciar o no la actividad sexual o a permitir o no la continuación de un embarazo precoz prematrimonial. El discurso cultural sobre la actividad sexual de los adolescentes puede tener también repercu- sión directa en las decisiones sobre la actividad sexual y reproductiva, con lo que define el contexto normativo de la fecundidad o el embarazo. Las influencias sociales inciden también en los familiares, los pares, la pareja, los maestros y los medios de comunicación. La influencia de la familia se manifiesta por medio de su estructura, la supervisión del comportamiento por los padres y el poder que es capaz de ejercer en las decisiones de la adolescente acerca de las relaciones románticas, el matrimonio, las relaciones sexuales y el embarazo.

\section{Fuentes de información}

El universo de estudio está constituido por la población adolescente de las ciudades de Santa Fe de Bogotá y Cali. En 2003, Bogotá, capital del país, contaba con cerca de 7 millones de habitantes, mientras que Cali, tercera ciudad en importancia, tenía 2,4 millones (5). Por su ubicación geográfica, Bogotá recibe la influencia de la cultura andina, más cerrada e introvertida, mientras que Cali tiene influencia de la cultura de la costa del Pacífico, más abierta y extrovertida. La edad mediana de la población femenina es de 7,3 años en Bogotá y de 5,9 años en Cali; es decir, la población femenina de esta última es más joven. Este dato, de hecho, podría asociarse con una mayor escolaridad en Bogotá que en Cali; de estas poblaciones, $16 \%$ y $12,8 \%$, respectivamente, han alcanzado el nivel universitario.

El estudio utiliza información secundaria generada por la encuesta de salud de los adolescentes de 2003, realizada en Cali y Bogotá por el Centro de Estudios sobre Desarrollo Económico (CEDE) de Colombia. Esta tuvo dos componentes: una encuesta cuantitativa de historia de vida y una entrevista cualitativa a profundidad. La encuesta cuantitativa de historia de vida se basó en un cuestionario estructurado que recoge dos conjuntos de información: las características sociodemográficas de todos los miembros de la familia o familias de las viviendas seleccionadas, y las historias de vida 
de una cohorte de mujeres de 13 a 19 años de edad. 4 Las historias de vida recogen información en cada una de las dimensiones relacionadas con los factores determinantes próximos (uniones, uso de métodos de planificación familiar, otros embarazos) y socioeconómicos (educación, corresidencia, empleo, migración). La encuesta cuantitativa contó con una muestra probabilística y estratificada reunida en dos etapas, con conglomerados desiguales. La muestra se compuso de 550 adolescentes en Cali y 550 en Bogotá, representativas de cada estrato socioeconómico. ${ }^{5}$ La entrevista cualitativa se dirigió a profundizar y valorar cualitativamente los resultados del análisis cuantitativo de los factores determinantes socioeconómicos de la fecundidad. Se le aplicó a una submuestra de las adolescentes que habían proporcionado su historia de vida, seleccionadas conforme a una búsqueda deliberada de diversidad dentro de la población de interés. Se efectuaron 72 entrevistas a profundidad y 4 grupos focales. Se realizó un total de 48 entrevistas a mujeres, 24 por ciudad. Se entrevistó también a 12 hombres en Bogotá y a 12 en Cali, todos parejas de mujeres participantes que aceptaron proporcionar información que permitiera entrevistarlos. Se utilizó una guía escrita para obtener los relatos de los adolescentes de uno y otro sexo sobre sus antecedentes de vida sexual, sus métodos de toma de decisiones y los significados que atribuyen al embarazo y a la fecundidad en adolescentes, así como a sus factores determinantes próximos. Con la información organizada por temas y categorías, definidas en función de los propósitos del estudio, se identificaron las categorías que surgían de las pautas y recurrencias en los datos, con el fin de obtener patrones socioculturales por sexo, estrato y ciudad.

\footnotetext{
4 A partir de este punto, el término "adolescente" se refiere al grupo de mujeres de 13 a 19 años de edad.

5 El estrato socioeconómico, definido en el marco muestral por el Departamento Administrativo Nacional de Estadística (DANE) de Colombia, considera las condiciones físicas de la vivienda y su entorno.
}

\section{El modelo de factores determinantes de sucesos de la vida sexual}

De acuerdo con el marco teórico expuesto en la sección anterior, las condiciones socioeconómicas -individuales y contextuales - actúan sobre el nivel y el patrón etario de la fecundidad, a través de los factores determinantes próximos. Con excepción del nivel de fecundidad, cada uno de dichos factores (inicio de las relaciones sexuales, unión o matrimonio, uso de métodos de planificación familiar y práctica del aborto) requiere la toma de decisiones por parte del adolescente. La mujer adolescente debe decidir si comenzar o no las relaciones sexuales y, en caso de hacerlo, si se mantendrá sexualmente activa, y luego, si tener un hijo o utilizar métodos anticonceptivos, y en tal caso, qué método utilizar, o si debe casarse. Además, si ocurre un embarazo, deberá decidir entre abortar o continuarlo (si no se ha casado, deberá decidir también si lo hará o será madre soltera). El presente trabajo se concentra en el análisis de los factores determinantes socioeconómicos, micro y contextuales, de dos decisiones que debe enfrentar la adolescente: el inicio de las relaciones sexuales y el primer embarazo.

De acuerdo con el marco conceptual expuesto en la sección anterior, las decisiones que toman los jóvenes sobre su comportamiento sexual y reproductivo difieren según las oportunidades económicas, laborales y educativas que se prevén, la oferta de planificación familiar, la situación socioeconómica, las características personales y del hogar en el que viven, y las condiciones, normas sociales e influencia del medio o contexto social en que viven y crecen.

Puesto que se contaba con historias de vida completas, tanto en los determinantes próximos como en los socioeconómicos (residencia, educación, empleo, hogar), se utilizó un modelo de riesgo de tiempo discreto, mediante el cual se estimó la probabilidad de que una adolescente iniciara su vida sexual y tuviera un primer embarazo. Este criterio ofrece dos ventajas: por un lado, permite incluir variables independientes que varían en el transcurso del tiempo (como edad y asistencia a la escuela) y, por el otro, permite enfrentar el problema de las observaciones censuradas por la derecha. ${ }^{6}$ En el caso de las adolescentes que no habían cumplido los 20 años a la fecha de la encuesta, no se observa si experimentarán los sucesos (inicio de las relaciones sexuales, unión o matrimonio, embarazo, fecundidad) antes de cumplir los 20 años.

El modelo elegido es básicamente una regresión logística en que la variable dependiente es si la mujer experimenta o no el suceso de análisis (comienza su vida sexual o se embaraza por primera vez), a cada edad, desde el momento en que se expone al riesgo respectivo. Por tanto, la variable dependiente indica si el evento de análisis ocurrió a cada edad de exposición. La exposición al evento cambia según sea este. Así, en el modelo de inicio de las relaciones sexuales, la exposición al riesgo comienza a la edad de la primera menstruación. En el modelo del primer embarazo, la exposición empieza a la edad de inicio de las relaciones sexuales. En cada caso, una vez ocurrido el suceso, la adolescente sale del modelo. Por ejemplo, una adolescente de 17 años de edad a la fecha de la encuesta que tuvo su primera menstruación a los 12 años y su primera relación sexual a los 15 años, aporta cuatro observaciones: tres que indican que no tuvo relaciones a los 12, 13 ni 14 años, y una que indica que el suceso ocurrió a la edad de 15 años. Si en este caso la observación es censurada (p. ej., la adolescente no ha tenido relaciones sexuales), aporta cinco observaciones, según las cuales el suceso (relaciones sexuales) no ocurrió a los 12, 13, 14, 15 ni 16 años (no se incluye la edad de 17 años porque aún no ha terminado de vivirla).

De acuerdo con la extensión al tiempo discreto de los modelos de riesgo proporcional propuesta por Cox (14), el modelo logístico de un suceso (primera relación sexual, primer

\footnotetext{
6 Las "observaciones censuradas por la derecha" son aquellas en las cuales el suceso no ha ocurrido en el momento de la encuesta ni se sabe si ocurrirá o no, ni cuándo.
} 
embarazo, primer hijo) en una adolescente $i$ a la edad $t$, puede estimarse de la siguiente forma:

$$
\log \left[h_{t i} /\left(1-h_{t i}\right)\right]=a_{t}+X_{i}^{\prime} \beta,
$$

donde: $h_{t i}$ es la probabilidad condicionada de que la mujer $i$ experimente el suceso a la edad $t$, dado que no lo ha experimentado antes; $a_{t}$ es una función de la edad (una variable que cambia con el tiempo) y representa el logit de la función de riesgo base; $X_{i}$ es el vector de covariables (incluidas las que cambian con el tiempo o la edad), y $\beta$, es el vector correspondiente a los parámetros asociados que miden el efecto de las covariables en el logit de la probabilidad condicional. La interpretación de los parámetros sigue las líneas tradicionales de la regresión logística. Los efectos que varían con el tiempo se introducen como interacciones entre las covariables y el factor discreto $a_{t}$.

\section{RESULTADOS}

\section{La fecundidad en adolescentes y sus factores determinantes próximos}

Aproximadamente 7\% de las adolescentes de Bogotá y Cali han estado embarazadas alguna vez. Sin embargo, en ambas ciudades el patrón acumulado de fecundidad difiere mucho entre estratos (figura 2): las adolescentes del estrato bajo comienzan la maternidad a menor edad y se incorporan a ella con mayor intensidad que las del estrato alto. Así, el nivel y el patrón (en particular, la pendiente del patrón) de la fecundidad en la adolescencia son mucho mayores en el estrato bajo que en el estrato medio alto, en las dos ciudades. Las diferencias observadas por estrato cuando las adolescentes alcanzan los 17 años son enormes: mientras que $13 \%$ de las del estrato bajo ya habían comenzado su vida reproductiva, menos de $4 \%$ había hecho lo propio en el estrato medio alto. Es decir, a los 17 años las adolescentes del estrato bajo triplican con creces el patrón acumulado de las del estrato medio alto. Por supuesto, estas diferencias tan grandes entre estratos tienen repercusiones no solo en la fecundidad acumulada durante la vida, sino en las perspectivas de educación y trabajo de las adolescentes.

FIGURA 2. Proporción de adolescentes que han tenido su primera relación sexual, se han unido a un compañero, han quedado embarazados o son madres, según la edad

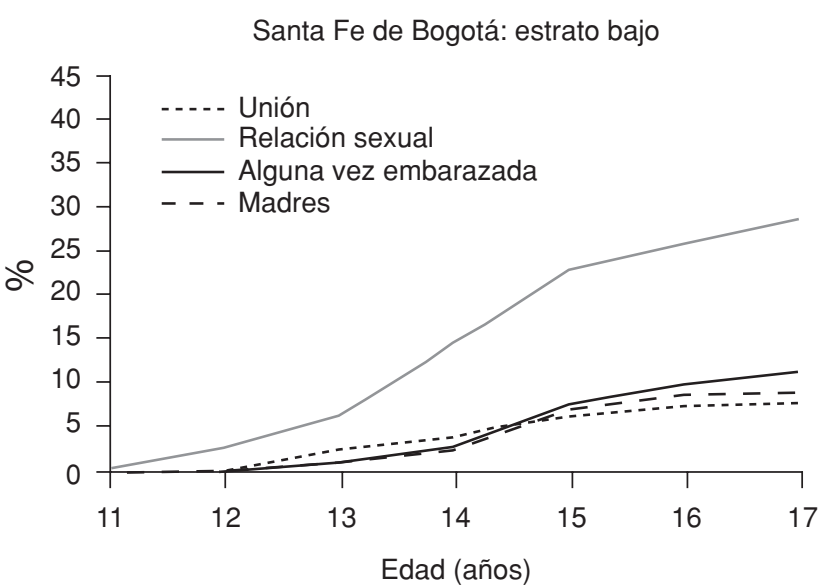

Cali: estrato bajo

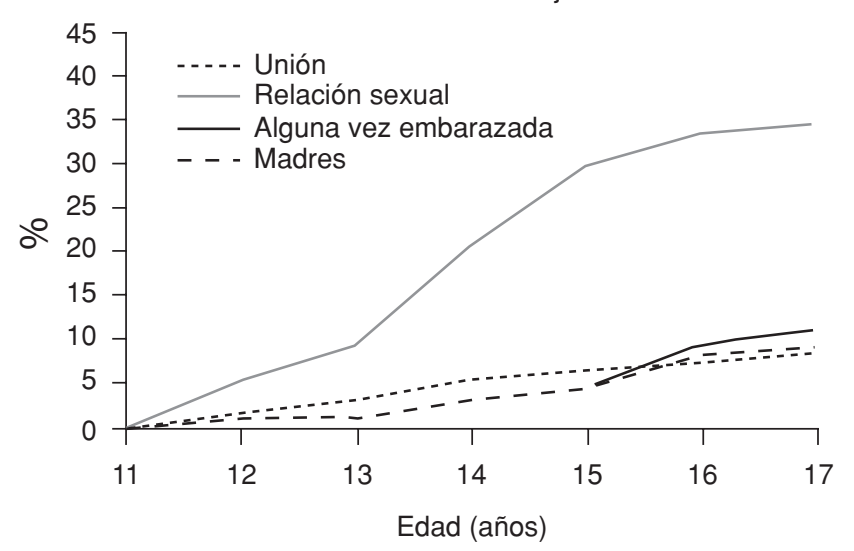

Santa Fe de Bogotá: estrato medio alto

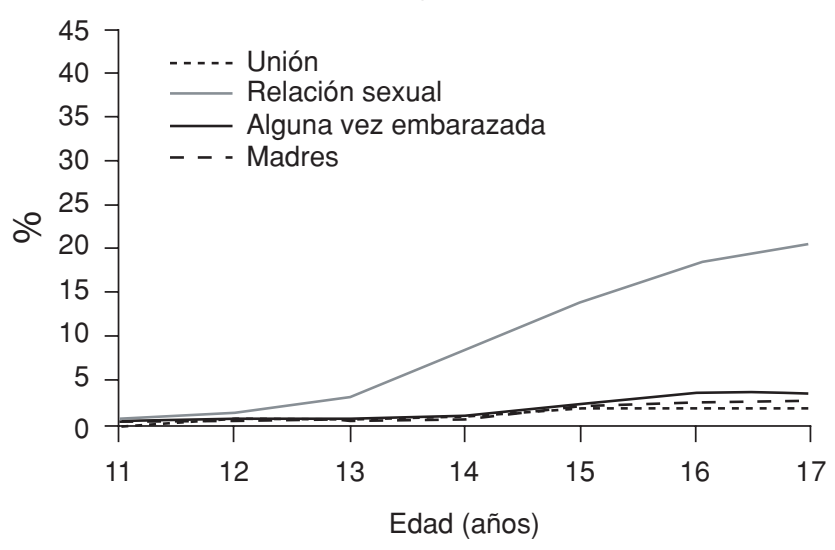

Cali: estrato medio alto

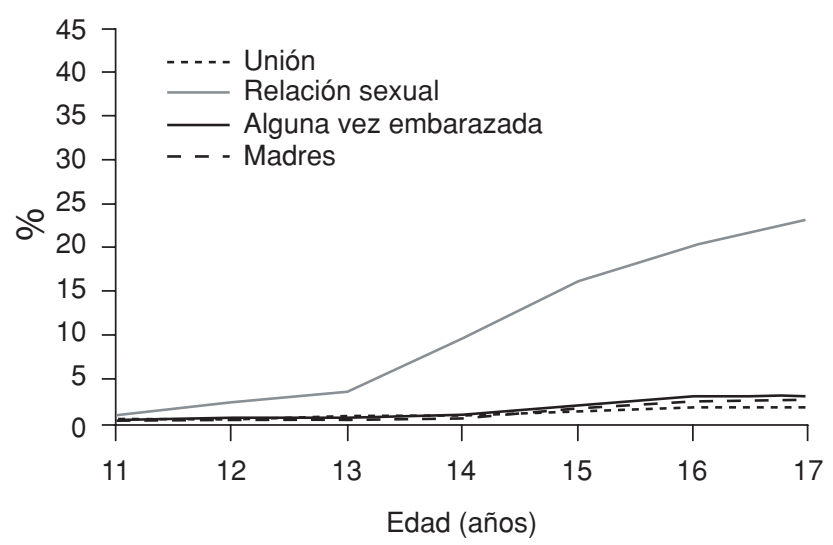

Fuente: Encuesta de salud de los adolescentes de 2003. Centro de Estudios sobre Desarrollo Económico (CEDE), Colombia. 
A pesar de que las dos ciudades presentan esas diferencias entre estratos, cada una muestra peculiaridades importantes. Aun cuando el nivel de fecundidad acumulada a los 17 años (13\%) es similar entre los estratos bajos de las dos ciudades, el patrón se muestra más cóncavo en Cali, lo que sugiere que en esta ciudad, si bien las adolescentes posponen un poco el inicio de la vida reproductiva, recuperan luego el tiempo, para igualarse a las de Bogotá. Así, aunque a los 15 años la fecundidad de las adolescentes del estrato bajo es mayor en Bogotá que en Cali, a los 17 años las tasas son similares entre las dos ciudades (figura 2). Entre las adolescentes del estrato medio alto, por el contrario, no hay diferencias entre ciudades en los patrones acumulados de fecundidad.

La exposición al embarazo está determinada por los patrones de nupcialidad (sea en unión legal o consensual) y por la actividad sexual de las mujeres solteras. La vida en unión ${ }^{7}$ de las adolescentes a edades tempranas es uno de los factores que inciden en su fecundidad. Hasta $6 \%$ de las adolescentes de Bogotá y Cali han vivido alguna vez en pareja. El patrón acumulado de nupcialidad (véase la figura 2) muestra diferencias por estrato similares a las de la fecundidad. Es decir, las adolescentes del estrato bajo establecen uniones estables mucho más temprano y con mayor frecuencia que las del estrato más alto. Sin embargo, entre las adolescentes del estrato bajo el patrón se incrementa mucho más temprano en Cali que en Bogotá, si bien las de ambas ciudades generan niveles similares a los 17 años. En el estrato más alto, por el contrario, como ocurre con la fecundidad, los patrones de unión son similares entre las ciudades. Así, tanto en Cali como en Colombia, cerca de $10 \%$ de las adolescentes del estrato bajo ya han establecido una unión estable a los 17 años, mientras que a esa edad lo han hecho solo $2 \%$ de las del estrato alto. Estos

\footnotetext{
El término abarca cualquier tipo de unión: legal (matrimonio civil o religioso) y consensual (unión de hecho, unión libre)
}

patrones denotan que las adolescentes del estrato bajo, en las dos ciudades, tienen mayor riesgo de embarazo que las del estrato alto, por su ingreso más temprano y resuelto a la formación de uniones estables.

La exposición al embarazo depende no solo de que exista una unión estable, sino también de la frecuencia de las relaciones previas a la formalización de una unión. Aunque la mayor parte de la actividad sexual ocurre dentro de la unión, estudios previos (2, 3) ponen de manifiesto que en Colombia, al igual que en Brasil, la proporción de mujeres sin vida en unión pero con una pareja sexual regular no es despreciable. La figura 2 permite comparar entre estratos la proporción de adolescentes que han tenido su primera relación antes de cada edad específica, por ciudad. En primer lugar, cerca de $30 \%$ de las adolescentes de las dos ciudades ya han iniciado su vida sexual (un porcentaje, por cierto, inferior a la norma social percibida). La información cualitativa puso de manifiesto que las adolescentes perciben las relaciones sexuales en la adolescencia como algo natural y esperable y, de hecho, se sienten presionadas a iniciarlas (15). En segundo lugar, el nivel de inicio de las relaciones sexuales es mucho mayor en Cali que en Bogotá, independientemente del estrato socioeconómico. Este resultado está en concordancia con las diferencias en los contextos familiar y sociocultural entre las ciudades: Bogotá tiene influencia de la cultura "cerrada" del altiplano cundiboyacense, mientras que Cali tiene influencia de la cultura "abierta" de la costa del Pacífico. En tercer lugar, aunque las adolescentes del estrato bajo inician las relaciones sexuales a menor edad y con mayor intensidad, las diferencias por estrato no son tan acentuadas como en el caso de la nupcialidad y la fecundidad. Así, en Bogotá, $24 \%$ de las adolescentes del estrato medio alto y $34 \%$ de las del estrato bajo ya han iniciado su vida sexual a los 17 años. En Cali, 42\% del estrato bajo y $29 \%$ del estrato medio alto ya lo han hecho a esa edad.

El nivel del patrón de inicio de las relaciones sexuales es claramente mayor que el del patrón de nupcialidad, en ambas ciudades y en ambos estratos, lo que implica una contribución de las relaciones sexuales prematrimoniales a la fecundidad de las adolescentes. Para dar mayor relieve a este dato, en la figura 2 se comparan los patrones acumulados de inicio de las relaciones sexuales, primera unión, primer embarazo y primer hijo, al interior de cada estrato y por ciudad.

Resaltan varios hechos. En primer lugar, las adolescentes del estrato bajo de las dos ciudades muestran un patrón más intenso y de inicio más temprano de la vida sexual, la unión y la maternidad, lo que indica que la mayor maternidad adolescente en este estrato se relaciona con el pronto inicio tanto de la actividad sexual como de la vida en pareja.

En segundo lugar, en las dos ciudades y en ambos estratos, el patrón de la primera unión está por encima del de la maternidad hasta los 15 años, pero a partir de esta edad el patrón de maternidad supera al de nupcialidad. Este hecho indica que las adolescentes que son madres antes de los 15 años se unen antes que las otras, pero que a partir de los 15 años muchas de las adolescentes tienen su primer hijo o su primer embarazo antes de formar su primera unión estable. Tal comportamiento se traduce en un elevado porcentaje de madres solteras: $48 \%$ de las adolescentes madres de Bogotá y $62 \%$ de las de Cali no tenían una unión estable (legal o consensual) cuando nació su primer hijo. Estas proporciones son mayores entre las adolescentes madres del estrato medio alto $(64 \%$ en Bogotá y $80 \%$ en Cali), que en las del estrato bajo ( $44 \%$ en Bogotá y $52 \%$ en Cali), lo que indica una mayor influencia de la nupcialidad en la fecundidad de las adolescentes del estrato bajo que en las del estrato medio alto.

En tercer término, en las dos ciudades y en ambos estratos, el patrón de inicio de las relaciones sexuales está muy por encima del de la fecundidad, lo que sugiere una influencia importante del uso de métodos de planificación familiar como medio de control de la fecundidad. Dicha influencia se muestra mucho más fuerte en Cali que 
en Bogotá, lo cual se explicaría por el mayor nivel del patrón de las relaciones sexuales en esta ciudad y las menores diferencias en la fecundidad.

La gran intensidad y el pronto inicio de las relaciones sexuales entre las adolescentes obliga a prestar especial atención a la primera relación sexual. Como se mencionó, una proporción mucho mayor de las adolescentes del estrato bajo que del estrato medio alto comienzan sus relaciones sexuales en la adolescencia. Entre las que ya iniciaron su vida sexual, la edad de la primera relación oscila entre los 15 y 16 años, independientemente del estrato y de la ciudad. El inicio de las relaciones sexuales ocurre típicamente dentro del marco de una relación romántica, con un joven que es 3 años mayor en promedio, tanto en Cali como en Bogotá. Solo entre $55 \%$ y $65 \%$ de las adolescentes usaron algún método de planificación familiar en su primera relación sexual. El uso de un método en la primera relación es más frecuente en el estrato medio alto que en el bajo, $\mathrm{y}$ las diferencias entre estratos son mucho mayores en Bogotá que en Cali. Así, solamente $43 \%$ de las adolescentes del estrato bajo y $72 \%$ de las del estrato alto usaron un método de este tipo en Bogotá, mientras que en Cali lo emplearon $60 \%$ de las del estrato bajo y $67 \%$ de las del más alto. Estos resultados se explican a la luz de la información cualitativa que pone de manifiesto algunos mitos en torno al uso de los métodos de planificación familiar en la primera relación sexual. En ambas ciudades la mayoría de las adolescentes entrevistadas en el estudio cualitativo, creen infundadamente que las mujeres no se embarazan en la primera relación sexual, ${ }^{8}$ que no es necesario el condón cuando los dos miembros de la pareja son vírgenes, que los métodos de protección no son eficaces y tienen efectos secundarios indeseables, y que utilizar condón con la persona que se ama constituye una falta de respeto.

\footnotetext{
8 Las mujeres adolescentes, al igual que los varones, creen que "a su edad no van a quedar embarazadas", que "no es necesario protegerse en la primera relación si los dos son vírgenes" y que "en la primera relación la mujer no se embaraza" (15).
}

El uso de métodos de planificación familiar entre las adolescentes empieza a los 16 años de edad en promedio, un año después de iniciarse las relaciones sexuales, lo cual significa que media un período de desprotección y de alto riesgo de embarazo. Una vez que empiezan a usarse métodos de planificación familiar, también el tipo que se use influye en el riesgo de embarazo. Las adolescentes, tanto en Bogotá como en Cali, escogen mayoritariamente el condón como primer método: en Bogotá, $72 \%$ de las del estrato medio alto y $54 \%$ de las del bajo; en Cali, $72 \%$ de las del estrato bajo y $61 \%$ de las del medio alto. Entre los métodos que siguen en orden de preferencia están los anticonceptivos orales, las inyecciones y los métodos naturales (retiro, ritmo), especialmente entre las adolescentes del estrato bajo de Bogotá.

A medida que aumenta la edad y con ella la frecuencia de las relaciones sexuales, aumenta también el uso de métodos de planificación familiar. Entre las adolescentes que ya iniciaron la actividad sexual el uso, alguna vez, de métodos de planificación familiar es relativamente alto; es mayor en Cali que en Bogotá y mayor entre las adolescentes del estrato medio alto que en las del bajo. Por lo menos $75 \%$ de las adolescentes del estrato bajo de Bogotá han utilizado alguna vez métodos de planificación familiar, por comparación con más de $90 \%$ de las del estrato medio alto. Estas diferencias entre ciudades y estratos refuerzan las observaciones acerca del inicio de las relaciones sexuales y el nivel de fecundidad: las adolescentes de Cali comienzan su vida sexual más temprano, pero usan más métodos de planificación familiar, de manera que sus niveles de fecundidad no son mayores que los de las adolescentes de Bogotá.

A pesar de que una menor proporción de adolescentes del estrato medio alto ya ha comenzado la actividad sexual y que una mayor proporción utiliza métodos de planificación familiar y una menor proporción son madres, destaca que una proporción importante de los pocos embarazos son prematrimoniales, lo que indica que probablemente se trate de embarazos no deseados, consecuencia de acciones no planificadas. Por el contrario, entre las adolescentes del estrato bajo, una mayor proporción ha iniciado su vida sexual, una mayor proporción se ha unido en pareja, una menor proporción usa métodos de planificación familiar (con mayor frecuencia porque así lo decide) y una mayor proporción son madres, pero se observa una menor incidencia de embarazos prematrimoniales, lo que denota que gran parte de la fecundidad se da dentro de la unión y es una fecundidad deseada. La información cualitativa indica que esta diferencia de comportamiento entre estratos se relaciona con las percepciones sobre la maternidad. Las adolescentes del estrato medio alto consideran que los hijos deben tenerse cuando se ha alcanzado estabilidad económica, emocional y en la relación de pareja, mientras que las del estrato bajo consideran que el embarazo en la adolescencia es un instrumento válido de reconocimiento y aceptación social, además de una opción para conformar una verdadera familia (15).

\section{Los factores determinantes socioeconómicos y contextuales de los sucesos de la vida sexual}

En este apartado se analizan los factores determinantes socioeconómicos y contextuales de dos acontecimientos: el inicio de las relaciones sexuales y el primer embarazo. El marco analítico presentado en una sección anterior contiene tres tipos de factores que influyen directa o indirectamente, a través de los factores determinantes próximos, en el nivel y patrón de la fecundidad en adolescentes. En primer lugar se analizan las políticas y programas gubernamentales respecto al sector de la salud y otros relacionados (educación, empleo), que se aplican a través de campañas de planificación familiar y promoción del acceso a la educación formal y a la educación sexual. En segundo lugar están los factores del contexto social y del hogar en que vive la adolescente. En tercero están sus características individuales. De acuerdo con este marco, se seleccionaron las varia- 
bles que más probablemente influyen en el inicio de las relaciones sexuales y en el primer embarazo. Entre las variables derivadas de acciones y políticas del gobierno se incluyeron: el acceso de la adolescente a los servicios de salud y a fuentes de información sobre sexualidad (aparatos reproductivos, reproducción, sexualidad, planificación familiar). Los datos de estas variables se capturaron al momento de la encuesta. Cabe esperar que un mayor acceso a los servicios de salud y una mayor información sobre sexualidad disminuyan la probabilidad de embarazo.

Como factores socioeconómicos del hogar se incluyeron el estrato socioeconómico, el clima educativo familiar, ${ }^{9}$ el acceso a la televisión de cable o a Internet, e información sociodemográfica de la madre: su escolaridad, edad al nacimiento del primer hijo, número de hijos y tipo de unión. De estas variables, el tipo de unión de la madre cambia con el tiempo, es decir, se modifica a lo largo de la vida de la adolescente (se basa en la historia vital). Se espera que una mayor escolaridad, mayor acceso a los medios de comunicación y características demográficas de la madre que reflejen una fecundidad menor y más tardía, lleven a una menor probabilidad de inicio de las relaciones sexuales y de embarazo.

Como factores contextuales del hogar se contemplaron las variables siguientes: fecundidad en la adolescencia en la familia, abuso sexual de la adolescente, agresión física familiar, violencia física o verbal, supervisión por los padres y nivel de comunicación con la madre. ${ }^{10}$ De estas variables, la violencia física o verbal cambia con la historia de vida de la joven. Es de es-

\footnotetext{
9 El clima educativo familiar se define como la escolaridad promedio, en años, de los miembros de la familia mayores de 15 años.

10 La fecundidad en la adolescencia en la familia es una variable sustitutiva (dummy) que indica si alguna de las hermanas u otras parientes cercanas ha tenido hijos antes de cumplir los 15 años. El abuso sexual, la agresión física y la violencia verbal son variables sustitutivas referidas a alguna experiencia relacionada con esos hechos. La supervisión de los padres se refiere a si la adolescente tiene horarios establecidos para salir y llegar a la casa. El nivel de comunicación con la madre se refiere a cuán bien se entiende o se comunica la adolescente con su madre.
}

perar que un contexto en que hay antecedentes familiares de fecundidad en la adolescencia, violencia familiar, baja supervisión por los padres y escasa comunicación con la madre, la probabilidad de embarazo en la adolescencia sea mayor.

Las características de la adolescente consideradas fueron su edad y la edad al cuadrado, ${ }^{11}$ el lugar de residencia, asistencia escolar y tipo de institución educativa, unión conyugal, uso de métodos de planificación familiar y empleo. Dado que la asistencia escolar y la nupcialidad varían con la edad, el estudio incluyó interacciones entre esas dos variables y la edad. Todas estas variables provienen de la historia de vida, que indica el estado de cada variable a cada edad. Es de esperar que vivir en una gran ciudad, estudiar en un colegio femenino, estar soltera y usar métodos modernos de planificación familiar disminuyan la probabilidad de embarazo.

\section{El inicio de las relaciones sexuales}

El cuadro 1 muestra los resultados del modelo de inicio de las relaciones sexuales, coeficientes estimados y elas-

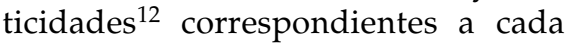
ciudad. Entre los factores resultantes de políticas y acciones del gobierno, la frecuencia de las charlas de educación sexual impartidas en las escuelas no ha mostrado efecto importante en ninguna ciudad. Por otra parte, la fuente de información sobre diferentes aspectos de la sexualidad tiene efectos diferentes según la ciudad, no siempre en el sentido esperado. En cuanto a la información sobre sexualidad, solamente la referente a los aparatos reproductivos obtenida de los padres o de la escuela tiene efectos favorables importantes. Por el contrario, la información sobre las relaciones sexuales o sobre

\footnotetext{
11 Para reducir la correlación con la variable original, esta se centró antes de elevarla al cuadrado.

12 Debido a que la escala de los coeficientes varía, se estimaron las elasticidades, calculadas en el promedio muestral de las variables independientes. La elasticidad mide el cambio porcentual en la variable dependiente como respuesta al cambio de una unidad porcentual en la variable independiente.
}

los métodos de planificación familiar no siempre tiene mucho impacto $\mathrm{o}$, cuando lo tiene, como en el caso de Bogotá, el efecto es el opuesto al esperado, es decir, que refuerza la probabilidad de embarazo en la adolescencia. Estos resultados se confirman con información cualitativa según la cual la educación sexual impartida en las escuelas es más bien informativa de los órganos reproductivos y de la prevención de enfermedades de transmisión sexual, pasando por alto las necesidades de formación integral de los adolescentes (15).

Respecto al conjunto de factores socioeconómicos del hogar (el estrato socioeconómico), mostraron efectos negativos estadísticamente significativos en ambas ciudades: pertenecer al estrato medio alto se asocia con una menor probabilidad de iniciar relaciones sexuales a cualquier edad. El clima educativo familiar en Cali y la escolaridad materna en Bogotá tienen efectos favorables estadísticamente significativos, en el sentido de que un mayor nivel o un mejor clima educativo se asocia con una menor probabilidad de inicio de las relaciones sexuales entre las adolescentes. La condición conyugal de la madre muestra asociaciones significativas solamente en Bogotá: el tener una madre sola (separada o viuda) incrementa la probabilidad de iniciar las relaciones sexuales.

Los factores contextuales del hogar constituyen el grupo de variables de mayor significación estadística. El antecedente de fecundidad adolescente en la familia, abuso sexual o agresión física familiar contra la adolescente, un bajo nivel de comunicación con la madre y la falta de supervisión de los padres se asocian de manera significativa, en las dos ciudades, con la probabilidad de inicio de la actividad sexual. El efecto de la supervisión por los padres tiene particular relevancia en Cali, mientras que en Bogotá sobresale el efecto del antecedente familiar de fecundidad en la adolescencia y de la falta de comunicación con la madre. Estos resultados apuntan a la subestimación que hasta el momento se ha hecho del efecto de los factores contextuales del hogar en los comportamientos de riesgo sexual de las adolescentes. 
CUADRO 1. Coeficientes y elasticidades estimados en el modelo del suceso de la primera relación sexual, por ciudad

\begin{tabular}{|c|c|c|c|c|}
\hline \multirow[b]{2}{*}{ Variables } & \multicolumn{2}{|c|}{ Coeficientes } & \multicolumn{2}{|c|}{ Elasticidades } \\
\hline & $\begin{array}{l}\text { Santa Fe } \\
\text { de Bogotá }\end{array}$ & Cali & $\begin{array}{l}\text { Santa Fe } \\
\text { de Bogotá }\end{array}$ & Cali \\
\hline \multicolumn{5}{|c|}{ Factores derivados de políticas y acciones del gobierno } \\
\hline \multicolumn{5}{|c|}{ Información sobre sistemas reproductivos recibida de: } \\
\hline Padres & $-0,773^{a}$ & $-0,581$ & $-0,151^{a}$ & $-0,098$ \\
\hline Escuela & $-0,198$ & $-0,768^{b}$ & $-0,141$ & $-0,546^{b}$ \\
\hline Otro (ref) & - & - & - & - \\
\hline \multicolumn{5}{|l|}{ Información sobre reproducción recibida de: } \\
\hline Padres & $-0,126$ & $-0,335$ & $-0,040$ & $-0,104$ \\
\hline Escuela & $0,445^{\mathrm{a}}$ & $-0,349^{a}$ & $0,236^{a}$ & $-0,173^{a}$ \\
\hline Otro (ref) & - & - & - & - \\
\hline \multicolumn{5}{|c|}{ Información sobre relaciones sexuales recibida de: } \\
\hline Padres & $0,567^{b}$ & $-0,075$ & $0,165^{b}$ & $-0,021$ \\
\hline Escuela & $0,658^{c}$ & $-0,047$ & $0,259^{c}$ & $-0,018$ \\
\hline Otro (ref) & - & - & - & - \\
\hline \multicolumn{5}{|c|}{ Información sobre planificación familiar recibida de: } \\
\hline Padres & $0,812^{c}$ & 0,358 & $0,162^{\mathrm{c}}$ & 0,080 \\
\hline Escuela & 0,032 & 0,490 & 0,018 & 0,255 \\
\hline Otro (ref) & - & - & & \\
\hline \multicolumn{5}{|l|}{ Intensidad de charlas de educación sexual: } \\
\hline Dos veces al año (ref) & - & - & - & - \\
\hline Una vez al año & $-0,437$ & 0,068 & $-0,065$ & 0,015 \\
\hline Una vez al mes & $-0,276$ & 0,036 & $-0,051$ & 0,005 \\
\hline Una vez a la semana & 0,163 & 0,162 & 0,043 & 0,006 \\
\hline No tuvo charlas & 0,449 & 0,455 & 0,034 & 0,015 \\
\hline \multicolumn{5}{|l|}{ Factores socioeconómicos de la familia } \\
\hline Estrato bajo (ref) & - & - & - & - \\
\hline Estrato medio alto & $-0,335^{a}$ & $-0,394^{b}$ & $-0,151^{a}$ & $-0,231^{b}$ \\
\hline Clima educativo del hogar & $-0,040$ & $-0,118^{c}$ & $-0,259$ & $-0,765^{\mathrm{c}}$ \\
\hline Cable o Internet & 0,203 & 0,202 & 0,121 & 0,187 \\
\hline \multicolumn{5}{|l|}{ Informacion sobre la madre } \\
\hline Edad promedio al tener el primer hijo & $-0,049$ & $-0,080^{\mathrm{a}}$ & $-0,163$ & $-0,236^{a}$ \\
\hline Número promedio de hijos & $-0,026$ & 0,010 & $-0,531$ & 0,195 \\
\hline \multicolumn{5}{|l|}{ Nivel educativo } \\
\hline Ninguno o primaria incompleta (ref) & - & - & - & - \\
\hline Primaria completa & $-0,764^{c}$ & $-0,035$ & $-0,189^{b}$ & $-0,006$ \\
\hline Bachillerato incompleto & $-0,860^{\mathrm{c}}$ & $-0,155$ & $-0,228^{c}$ & $-0,040$ \\
\hline Bachillerato completo o universidad & $-0,406$ & 0,101 & $-0,134$ & 0,035 \\
\hline \multicolumn{5}{|l|}{ Tipo de unión : } \\
\hline Unión consensual o no informa (ref) & - & - & - & - \\
\hline Matrimonio & $-0,203$ & $-0,207$ & $-0,085$ & $-0,069$ \\
\hline \multirow[t]{2}{*}{ Separada o viuda } & $0,567^{c}$ & 0,026 & $0,145^{c}$ & 0,006 \\
\hline & & & & (Continúa) \\
\hline
\end{tabular}

Entre las características de la adolescente, la edad tiene un efecto positivo importante y muy significativo, en el sentido de que la probabilidad de comenzar la vida sexual es altamente dependiente de esta variable. El lugar de residencia a lo largo de la vida tiene efectos contrarios en las dos ciudades. Por una parte, conforme a las encuestas realizadas, vivir en una ciudad grande, como Bogotá, conlleva una mayor probabilidad de iniciar más temprano las relaciones sexuales, en comparació con las regiones rurales o las ciudades de tamaño intermedio, mientras que en Cali ocurre lo contrario. Podría ser este un reflejo de las características diferentes de las corrientes migratorias que desembocan en cada una de estas ciudades. El estado conyugal de la adolescente, que cambia con la edad, muestra un efecto estadísticamente significativo solamente en Cali, lo que indica que en esta ciudad hay una relación estrecha entre el comienzo de las relaciones sexuales y el de la vida en pareja. Contra lo que se esperaría, la asistencia escolar por tipo de institución no tiene efectos significativos, ni del signo esperado, en la probabilidad de iniciar las relaciones sexuales.

Las elasticidades estimadas (véase el cuadro 1) indican que, aparte de la edad, los factores que más influyen en la probabilidad de iniciar las relaciones sexuales son los de carácter contextual. Así, la agresión física familiar contra la adolescente y la supervisión de los padres en Bogotá, y el nivel de 
CUADRO 1. (Continuación)

\begin{tabular}{|c|c|c|c|c|}
\hline \multirow[b]{2}{*}{ Variables } & \multicolumn{2}{|c|}{ Coeficientes } & \multicolumn{2}{|c|}{ Elasticidades } \\
\hline & $\begin{array}{l}\text { Santa Fe } \\
\text { de Bogotá }\end{array}$ & Cali & $\begin{array}{l}\text { Santa Fe } \\
\text { de Bogotá }\end{array}$ & Cali \\
\hline \multicolumn{5}{|l|}{ Factores contextuales de la familia } \\
\hline Fecundidad en la adolescencia en la familia & $0,498^{b}$ & 0,119 & $0,082^{b}$ & 0,022 \\
\hline Abuso sexual sufrido por la adolescente & $0,591^{b}$ & $0,656^{b}$ & $0,063^{c}$ & $0,032^{b}$ \\
\hline Agresión física familiar contra la adolescente & $0,516^{b}$ & $0,863^{c}$ & $0,401^{b}$ & $0,673^{\circ}$ \\
\hline Violencia verbal o física contra la adolescente & 0,365 & 0,384 & 0,039 & 0,034 \\
\hline Acuerdo sobre la hora de llegada & $-0,266$ & $-0,582^{c}$ & $-0,186$ & $-0,414^{\mathrm{c}}$ \\
\hline \multicolumn{5}{|l|}{ Comunicación con la madre: } \\
\hline Por lo general (ref) & - & - & - & - \\
\hline Siempre & 0,009 & $-0,294$ & 0,002 & $-0,029$ \\
\hline Nunca & $0,761^{\mathrm{c}}$ & 0,159 & $0,366^{c}$ & 0,094 \\
\hline \multicolumn{5}{|l|}{ Características de la adolescente } \\
\hline Edad & $1,283^{c}$ & $1,147^{c}$ & $16,604^{\mathrm{c}}$ & $14,443^{\mathrm{c}}$ \\
\hline Edad $^{2}$ & $-0,058^{b}$ & $-0,022$ & $-0,202^{b}$ & $-0,079$ \\
\hline \multicolumn{5}{|l|}{ Lugar de residencia } \\
\hline Rural o ciudad intermedia (ref) & - & - & - & - \\
\hline Nativa o ciudad principal & $0,721^{c}$ & $-0,472^{a}$ & $0,534^{\mathrm{c}}$ & $-0,379^{a}$ \\
\hline \multicolumn{5}{|l|}{ Tipo de institución educativa } \\
\hline Femenina & 1,330 & 0,416 & 0,213 & 0,057 \\
\hline Mixta & 1,568 & 0,874 & 1,061 & 0,626 \\
\hline No estudia (ref) & - & - & - & - \\
\hline Edad no estudia & 0,177 & 0,092 & 0,328 & 0,114 \\
\hline \multicolumn{5}{|l|}{ Unión de la adolescente } \\
\hline No unida (ref) & - & - & - & - \\
\hline Unida & 0,130 & $9,330^{\mathrm{c}}$ & 0,018 & $0,101^{c}$ \\
\hline Edad unión & $-0,139$ & $-0,448^{a}$ & $-0,030$ & $-0,069^{a}$ \\
\hline \multicolumn{5}{|l|}{ Empleo } \\
\hline Tiempo completo & $-0,629^{a}$ & 0,008 & $-0,021^{a}$ & 0,000 \\
\hline Tiempo parcial & 0,172 & 0,027 & 0,007 & 0,001 \\
\hline No trabaja (ref) & - & - & - & - \\
\hline Constante & $-22,264^{c}$ & $-17,351^{\mathrm{c}}$ & & \\
\hline No. de observaciones & 2170 & 2247 & & \\
\hline $\mathrm{Ji}^{2} \mathrm{RV}(38)$ & $790,64^{c}$ & $795,95^{c}$ & & \\
\hline$\left(\right.$ Seudo-R) ${ }^{2}$ & 0,423 & 0,382 & & \\
\hline Log verosim & $-539,98$ & $-643,67$ & & \\
\hline
\end{tabular}

a $P<0,1$.

${ }^{b} P<0,05$.

${ }^{c} P<0,01$.

d $\mathrm{Ji}^{2} \mathrm{RV}$, ji al cuadrado de la razón de verosimilitud.

e Log verosim, logaritmo de máxima verosimilitud.

comunicación con la madre en Cali, son las variables de mayor impacto en el inicio de la vida sexual de la adolescente. De los demás factores contemplados, el clima educativo familiar en Cali y la escolaridad materna en Bogotá tienen elasticidades altas. La información sobre el aparato reproductor proporcionada por los padres o las escuelas tiene elasticidades relativamente altas, ante todo en Cali, lo que demuestra un efecto importante de estos programas. Por el contrario, no mostró elasticidad importante ni la in- formación sobre otros factores de la sexualidad ni la intensidad de la educación sexual en las escuelas, poniéndose de manifiesto la escasa repercusión de los programas de educación sexual que, de acuerdo con la ley, se imparten en el medio escolar.

\section{El primer embarazo}

El cuadro 2 resume los resultados del modelo del primer embarazo, coeficientes y elasticidades estimadas, en lo que respecta a cada ciudad. Del grupo de factores derivados de políticas y acciones del gobierno, el acceso a los servicios de salud es altamente significativo en las dos ciudades. Sin embargo, la variable presenta el signo opuesto al esperado: un mayor acceso se vincula a una mayor probabilidad de embarazo. Ya que se trata de una variable de corte transversal (al momento de la encuesta), su efecto contrario podría interpretarse en el sentido de que se recurre a los servicios de salud por reacción al embarazo en la adolescente. 
CUADRO 2. Coeficientes y elasticidades estimados en el modelo del evento primer embarazo, por ciudad

\begin{tabular}{|c|c|c|c|c|}
\hline \multirow[b]{2}{*}{ Variables } & \multicolumn{2}{|c|}{ Coeficientes } & \multicolumn{2}{|c|}{ Elasticidades } \\
\hline & $\begin{array}{l}\text { Santa Fe } \\
\text { de Bogotá }\end{array}$ & Cali & $\begin{array}{l}\text { Santa Fe } \\
\text { de Bogotá }\end{array}$ & Cali \\
\hline \multicolumn{5}{|c|}{ Factores derivados de políticas y acciones del gobierno } \\
\hline \multicolumn{5}{|l|}{ Acceso a servicios de salud: } \\
\hline No ha utilizado (ref) & - & - & - & - \\
\hline Ha utilizado & $2,384^{\mathrm{a}}$ & $1,363^{a}$ & $1,1081^{\mathrm{a}}$ & $0,676^{\mathrm{a}}$ \\
\hline \multicolumn{5}{|c|}{ Información sobre el aparato reproductor recibida de: } \\
\hline Padres & $3,052^{a}$ & 1,646 & $0,425^{\mathrm{a}}$ & 0,228 \\
\hline Escuela & $3,996^{a}$ & $2,112^{c}$ & $3,094^{\mathrm{a}}$ & $1,591^{c}$ \\
\hline Otro (ref) & - & - & - & - \\
\hline \multicolumn{5}{|l|}{ Información sobre reproducción recibida de: } \\
\hline Padres & $-1,220$ & $-0,490$ & $-0,342$ & $-0,119$ \\
\hline Escuela & $-0,924$ & 0,028 & $-0,551$ & 0,016 \\
\hline Otro (ref) & - & - & - & - \\
\hline \multicolumn{5}{|c|}{ Información sobre relaciones sexuales recibida de: } \\
\hline Padres & $2,329^{a}$ & 0,689 & $0,620^{a}$ & 0,159 \\
\hline Escuela & $1,416^{\mathrm{b}}$ & $-0,134$ & $0,580^{b}$ & $-0,056$ \\
\hline Otro (ref) & - & - & - & - \\
\hline \multicolumn{5}{|c|}{ Información sobre planificación familiar recibida de: } \\
\hline Padres & $-2,950^{\mathrm{a}}$ & $-0,246$ & $-0,683^{a}$ & $-0,050$ \\
\hline Escuela & $1,682^{\mathrm{a}}$ & $-0,407$ & $0,813^{\mathrm{a}}$ & $-0,205$ \\
\hline Otro (ref) & - & - & - & - \\
\hline Dos veces al año (ref) & - & - & - & - \\
\hline Una vez al año & 0,119 & 0,875 & 0,011 & 0,170 \\
\hline Una vez al mes & $-0,355$ & 0,931 & $-0,056$ & 0,137 \\
\hline Una vez a la semana & 0,949 & 0,915 & 0,311 & 0,380 \\
\hline No tuvo charlas & 0,265 & $2,999^{b}$ & 0,032 & $0,147^{b}$ \\
\hline \multicolumn{5}{|l|}{ Factores socioeconómicos del hogar } \\
\hline \multicolumn{5}{|l|}{ Ciudad (Bogotá = 1) } \\
\hline Estrato bajo (ref) & - & - & - & - \\
\hline Estrato medio alto & $-0,422^{\mathrm{c}}$ & $-0,924^{c}$ & $-0,146^{c}$ & $-0,450^{c}$ \\
\hline Clima educativo del hogar & $-0,901^{\mathrm{a}}$ & $-0,409^{a}$ & $-5,576^{a}$ & $-2,534^{\mathrm{a}}$ \\
\hline Cable o Internet & 0,074 & $-0,214$ & 0,038 & $-0,170$ \\
\hline \multicolumn{5}{|l|}{ Información sobre la madre } \\
\hline Edad promedio al tener el primer hijo & 0,178 & $-0,332^{a}$ & 0,665 & $-1,157^{a}$ \\
\hline Número promedio de hijos & $-0,035$ & $-0,013$ & $-0,728$ & $-0,262$ \\
\hline \multicolumn{5}{|l|}{ Nivel educativo } \\
\hline Ninguno o primaria incompleta (ref) & - & - & - & - \\
\hline Primaria completa & 0,798 & $1,548^{b}$ & 0,248 & $0,356^{\mathrm{b}}$ \\
\hline Bachillerato incompleto & 0,642 & $2,197^{a}$ & 0,177 & $0,643^{a}$ \\
\hline Bachillerato completo o universidad & 1,271 & $1,670^{\mathrm{b}}$ & 0,297 & $0,435^{b}$ \\
\hline \multicolumn{5}{|l|}{ Tipo de unión } \\
\hline Unión consensual o no informa (ref) & - & - & - & - \\
\hline Matrimonio & 0,231 & $1,034^{c}$ & 0,079 & $0,290^{c}$ \\
\hline \multirow[t]{2}{*}{ Separada, viuda o finada } & 0,234 & $1,546^{a}$ & 0,084 & $0,487^{a}$ \\
\hline & & & & (Continúa) \\
\hline
\end{tabular}

Tal interpretación sería acorde al papel positivo que ha venido desempeñando la oferta creciente de servicios de salud sexual por conducto de las instituciones públicas y también de las organizaciones no gubernamentales (ONG).

El grupo de variables relacionadas con la información sobre diferentes aspectos de la sexualidad no muestra un comportamiento coherente. De una parte, la información sobre el aparato reproductor y las relaciones sexuales, impartida tanto por los padres como por la escuela, es significativa pero del signo opuesto - aumenta la probabilidad de embarazo-, lo cual denota que dicha información suscita inquietudes, más que resolverlas. De otra, la información sobre planificación familiar es significativa solamente en Bogotá, pero con el signo negativo solo en el caso de la información impartida por los padres. El efecto de la información sobre métodos de planificación familiar que se imparte en las escuelas, por el contrario, tiene un efecto significativo pero contrario al deseado en la probabilidad de embarazo entre las adolescentes de Bogotá. Las charlas de educación sexual en las escuelas no contribuyen mayormente a disminuir la probabilidad de un primer embarazo. También estos resultados ponen de manifiesto el 
CUADRO 2. (Continuación)

\begin{tabular}{|c|c|c|c|c|}
\hline \multirow[b]{2}{*}{ Variables } & \multicolumn{2}{|c|}{ Coeficientes } & \multicolumn{2}{|c|}{ Elasticidades } \\
\hline & $\begin{array}{l}\text { Santa Fe } \\
\text { de Bogotá }\end{array}$ & Cali & $\begin{array}{l}\text { Santa Fe } \\
\text { de Bogotá }\end{array}$ & Cali \\
\hline \multicolumn{5}{|l|}{ Factores contextuales del hogar } \\
\hline Fecundidad en la adolescencia en la famila & $1,326^{b}$ & $1,165^{b}$ & $0,258^{b}$ & $0,250^{b}$ \\
\hline Abuso sexual sufrido por la adolescente & 0,344 & $-3,267^{c}$ & 0,049 & $-0,354^{c}$ \\
\hline Agresión física familiar contra la adolescente & $2,271^{\mathrm{c}}$ & $1,790^{\mathrm{b}}$ & $1,990^{c}$ & $1,572^{b}$ \\
\hline Violencia verbal o física & $-0,750$ & $-1,206$ & $-0,103$ & $-0,112$ \\
\hline Acuerdo sobre la hora de llegada & $-3,139^{c}$ & $-0,503$ & $-1,922^{c}$ & $-0,314$ \\
\hline \multicolumn{5}{|l|}{ Comunicación con la madre } \\
\hline Por lo general (ref) & - & - & - & - \\
\hline Siempre & 0,044 & $-2,133^{b}$ & 0,011 & $-0,285^{b}$ \\
\hline Nunca & $2,922^{c}$ & $-0,110$ & $1,436^{c}$ & $-0,063$ \\
\hline \multicolumn{5}{|l|}{ Caracteristicas de la adolescente } \\
\hline Edad & $1,835^{a}$ & $0,644^{a}$ & $28,822^{a}$ & $9,931^{a}$ \\
\hline Edad $^{2}$ & $-0,288^{b}$ & 0,075 & $-0,610^{b}$ & 0,201 \\
\hline \multicolumn{5}{|l|}{ Lugar de residencia } \\
\hline Rural o ciudad intermedia (ref) & - & - & - & - \\
\hline Nativa o ciudad principal & $-1,227^{b}$ & $-1,059^{c}$ & $-0,919^{b}$ & $-0,833^{\circ}$ \\
\hline \multicolumn{5}{|l|}{ Tipo de institucion educativa } \\
\hline Femenina & $-0,998$ & 3,488 & $-0,076$ & 0,236 \\
\hline Mixta & $-3,530$ & 1,136 & $-1,757$ & 0,625 \\
\hline No estudia (ref) & - & - & - & - \\
\hline Edad no estudia & $-0,177$ & 0,222 & $-1,203$ & 1,301 \\
\hline \multicolumn{5}{|l|}{ Unión de la adolescente } \\
\hline No unida (ref) & - & - & - & - \\
\hline Unida & 3,331 & $-3,821$ & 0,484 & $-0,517$ \\
\hline Edad unión & $-0,038$ & 0,318 & $-0,087$ & 0,679 \\
\hline \multicolumn{5}{|l|}{ Metodos de planificacion familiar } \\
\hline No usa (ref) & - & - & - & - \\
\hline Modernos & 0,023 & $-0,621$ & 0,007 & $-0,251$ \\
\hline Tradicionales & 0,893 & $-1,921^{b}$ & 0,027 & $-0,143^{b}$ \\
\hline \multicolumn{5}{|l|}{ Empleo } \\
\hline Tiempo completo & 0,614 & $-0,195$ & 0,058 & $-0,015$ \\
\hline Tiempo parcial & 0,959 & 0,504 & 0,108 & 0,043 \\
\hline No trabaja (ref) & - & - & - & - \\
\hline Constante & $-31,891^{a}$ & $-16,749^{a}$ & & \\
\hline No. de observaciones & 483 & 578 & & \\
\hline $\mathrm{Ji}^{2} \mathrm{RV}(41)^{\mathrm{d}}$ & $230,75^{a}$ & $209,59^{a}$ & & \\
\hline (Seudo- $R^{2}$ ) & 0,524 & 0,444 & & \\
\hline Log verosime & $-104,65$ & $-131,22$ & & \\
\hline
\end{tabular}

limitado efecto que ha tenido en las adolescentes la educación sexual que se imparte en las escuelas desde 1993.

El grupo de factores socioeconómicos del hogar revela un efecto importante y significativo del estrato y del clima educativo familiar en las dos ciudades: pertenecer al estrato medioalto y un mejor clima educativo se asocian con una menor probabilidad de un primer embarazo. Contra lo espe- rado, la escolaridad materna se asocia con una mayor probabilidad de embarazo, especialmente en Cali. Este resultado, aparentemente contradictorio, podría guardar relación con el efecto negativo que tiene en el comportamiento de las adolescentes la participación laboral de la mujer, especialmente en el caso de las madres de escolaridad alta. Ruhm (16) encuentra, en el caso de Estados Unidos, que la incorporación de las madres a la fuerza laboral tiene efectos negativos en las adolescentes "favorecidas", es decir, aquellas cuyas madres tienen alta escolaridad y participan más en la fuerza laboral y durante un mayor número de horas. Tal vez pueda darse una interpretación similar a los resultados colombianos.

El tipo de unión que ha formado la madre tiene un efecto adverso de 
grado significativo en Cali, en el sentido de que las adolescentes de madres separadas o divorciadas tienen mayor probabilidad de embarazarse antes, tal vez por la participación de un menor número de personas en la supervisión de los hijos.

Las variables consideradas entre los factores contextuales del hogar son, en conjunto, las de mayor impacto y significación estadística. En las dos ciudades, los antecedentes de fecundidad en la adolescencia en la familia, la agresión física familiar y un bajo nivel de comunicación con la madre se asocian en grado significativo con una mayor probabilidad de un primer embarazo en la adolescente. La supervisión de los padres es particularmente relevante en Bogotá, en el sentido de que la aplicación de controles se asocia con una probabilidad mucho menor de que ocurra el primer embarazo en la adolescencia.

Entre las características de la adolescente, la edad tiene un efecto directo significativo, particularmente en Bogotá. En este aspecto, se advierte una incorporación a la maternidad más pronta entre las adolescentes de Bogotá que entre las de Cali. El lugar de residencia indica, tanto en Bogotá como en Cali, que vivir en una gran ciudad se asocia, a cada edad, con una mayor probabilidad de un primer embarazo en la adolescencia. Esto podría vincularse a una mayor apertura ideológica y a una mayor aceptación de los métodos de planificación familiar que en las regiones rurales.

El uso de métodos de planificación familiar no se asocia con los efectos esperados. En Bogotá la variable no muestra diferencias estadísticamente significativas. En Cali, aunque la asociación tiene el signo esperado, es mayor en el caso de los métodos tradicionales (naturales, folclóricos) que en el de los modernos, contra lo que se esperaría. Este resultado podría entenderse a la luz de la información cualitativa que revela, como se vio líneas antes, las creencias infundadas, comunes entre los adolescentes, de que los métodos modernos de protección no son eficaces $\mathrm{y}$ pueden tener efectos secundarios indeseables, además de que proponerle a la persona amada que use alguno, como el condón, constituye una falta de respeto (15).

Las elasticidades estimadas en el suceso del primer embarazo (cuadro 2) ponen de manifiesto, en las dos ciudades, que de todas las variables contempladas, excepto la edad, las de mayor asociación estadística en la probabilidad de un primer embarazo en la adolescencia son el clima educativo familiar, la escolaridad materna, el antecedente de fecundidad en la adolescencia en la familia, la agresión física familiar y el nivel de supervisión por los padres. Ya que esas son las variables de mayor trascendencia entre todos los conjuntos de factores contemplados, incluidos los de tipo contextual y socioeconómico familiar, salta a la vista la necesidad de fomentar la participación de la familia y la supervisión de los padres en lo referente al comportamiento reproductivo de las adolescentes.

\section{Evaluación cualitativa de los factores determinantes del embarazo en la adolescencia ${ }^{13}$}

Los resultados de las entrevistas cualitativas refuerzan las pruebas cuantitativas de que los conceptos individuales influyen en los factores determinantes de la fecundidad. En el proceso de socialización los jóvenes se forman los conceptos o nociones que guían sus decisiones respecto a las relaciones sexuales en la adolescencia, el uso de métodos de planificación familiar, unirse o casarse, embarazarse, tener un hijo o abortar. Los datos cualitativos de las dos ciudades ratifican que el dimorfismo sexual evidente determina haya un trato diferente para hombres y mujeres, que aún persista el doble estándar respecto a lo que se espera de cada sexo y que prevalezcan la polarización y la inequidad en las relaciones de género. Estas diferencias determinadas por el género influyen en el proceso de formación de la identidad en la adolescencia, proceso que in-

\footnotetext{
13 Esta sección se basa en los resultados del estudio cualitativo realizado (15).
}

cide, a su vez, en las decisiones que los jóvenes toman respecto a su vida sexual y reproductiva.

Al evaluar el inicio temprano de la actividad sexual es importante considerar la creencia generalizada entre los jóvenes de que las relaciones sexuales son naturales y normales en la adolescencia y que es poco probable que una pareja no las tenga. Asociados a la falta de utilización de métodos de planificación familiar se encontraron los siguentes: a) la percepción de invulnerabilidad; b) escepticismo respecto a la eficacia de los métodos; c) creencias infundadas sobre sus efectos secundarios; d) la convicción de que proponer el uso del condón a la persona que se ama - a quien se le tiene confianzaes una falta de respeto; e) la idea de que con un condón no se siente lo mismo o que este debe usarse solamente con mujeres que no son vírgenes. En cuanto a la maternidad, algunos conceptos compiten con la idea de que los hijos deben tenerse cuando se ha alcanzado estabilidad económica, emocional y de pareja, a saber: a) la percepción de que el embarazo en la adolescencia es una forma de adquirir "estatus", reconocimiento y aceptación social; b) la creencia de que el embarazo constituye una opción para conformar una "verdadera familia"; c) la convicción, entre las mujeres, de que la maternidad es un elemento central de la identidad femenina $\mathrm{y}$, entre los varones, de que el embarazo de la pareja confirma su masculinidad, su madurez y su capacidad reproductiva; d) la valoración de los hijos como fuente de autorrealización y trascendencia y de seguridad afectiva, económica y social; e) la idea de que el aborto es un asesinato y que si una pareja decidió tener relaciones sexuales debe asumir las consecuencias de sus acciones.

Además, se logró establecer que la ambigüedad, y a veces contradicción, en los mensajes que trasmiten los distintos agentes sociales determina que en los adolescentes coexistan actitudes contradictorias hacia la sexualidad, lo cual afecta gravemente su juicio y su capacidad para tomar decisiones de una manera lógica, racional y sistemática, utilizando estrategias planeadas 
cuidadosamente y con una clara orientación futura. Se observó también que en las decisiones de las adolescentes y sus parejas predominan la dependencia y la aplicación de estrategias intuitivas o espontáneas en función de los sentimientos del momento. Los datos de las adolescentes que dijeron no haber comenzado la actividad sexual pusieron de manifiesto que al tomar decisiones acerca de su vida sexual algunos jóvenes tienden a poner en tela de juicio las normas sociales en torno a la práctica sexual en la adolescencia, con una fuerte inclinación por sus propios intereses, creencias, actitudes, valores y metas.

Los datos indican que los jóvenes que tienen más dificultades para planear sus decisiones presentan deficiencias en por lo menos dos aspectos: la confianza en sí mismos y la autodeterminación. Es decir, no han contado con un ambiente propicio para desarrollar la convicción personal de que pueden asumir el control de los acontecimientos, elegir entre opciones $\mathrm{y}$ cambiar las situaciones que se les presentan, para satisfacer mejor sus expectativas y necesidades.

Al igual que lo observado en otras investigaciones, los adolescentes comienzan a tener sus experiencias sexuales dentro del marco de las relaciones románticas, lo cual constituye un contexto óptimo para ello. Sin duda, en lo que se refiere a la actividad sexual, las relaciones románticas ofrecen a los adolescentes de aprendizaje de suma importancia que, dependiendo de la edad a la que ocurran, de su naturaleza y calidad, pueden conducirlos o no a una sexualidad satisfactoria, así como a la toma de decisiones bien planeadas y sistemáticas en torno a su vida sexual y reproductiva.

Los resultados obtenidos indican que las decisiones que toman las jóvenes en torno a su vida sexual y reproductiva se relacionan con la formulación y realización de su proyecto de vida, el cual, como es evidente, influye a su vez en su fecundidad. Según se desprende de las entrevistas a estos jóvenes, cuando no se han formulado metas profesionales y en torno a la incorporación al mundo la- boral, las cuales son fundamentales para la orientación hacia el futuro, se incrementa el riesgo de embarazo, porque las adolescentes encuentran en la nupcialidad y en la maternidad su principal fuente de realización personal. Sin embargo, debe tenerse en cuenta que, según logró establecerse, existe también una relación entre las condiciones socioeconómicas y las metas y aspiraciones de los jóvenes. Destaca también que los hombres y mujeres que centraron su proyecto de vida en la nupcialidad, la maternidad y la paternidad solían pertenecer al estrato bajo.

\section{CONCLUSIONES Y REFLEXIONES}

Entre los estratos socioeconómicos se observan grandes diferencias en los patrones de actividad sexual, unión y maternidad, tanto en Bogotá como en Cali, no solo en relación con la edad en que se inician, sino también con el patrón por edad. Se aprecia una mayor frecuencia de maternidad en las adolescentes del estrato bajo, a consecuencia de un inicio temprano de las relaciones sexuales y de las uniones y de una menor disposición al uso de métodos de planificación familiar. Este comportamiento se asocia con las diferencias por estrato observadas en los conceptos que tienen las adolescentes sobre la maternidad, el deseo de satisfacer las necesidades afectivas y el de obtener un proyecto de vida.

Los resultados apuntan a la existencia de un mito en torno al inicio de las relaciones sexuales entre adolescentes: aunque menos de la tercera parte de las adolescentes estudiadas habían comenzado la actividad sexual, existe la creencia generalizada de que las relaciones sexuales son comunes en la adolescencia. Este mito tiene implicaciones en el comportamiento sexual de las mujeres adolescentes, porque estas conceden gran importancia a la norma percibida y al comportamiento de sus pares. Los amigos, los pares, los medios de comunicación y la sociedad en su conjunto fomentan la idea de que la actividad sexual en las adolescentes es un hecho común y "natural" para la edad. Además de ponérseles presión para volverse sexualmente activas, se les pide que "se cuiden", aun cuando ni en el nivel familiar ni en el de las instituciones pertinentes (escuela y servicios de salud) se les proporcionan el apoyo y asesoramiento necesarios y apropiados para la toma de decisiones en este aspecto, ni para el uso adecuado de métodos de planificación familiar. En este sentido, los medios de comunicación masiva, en particular la televisión, serían valiosos instrumentos para transmitir las normas y valores sociales en torno a los comportamientos sexuales aceptables y permisibles en los adolescentes. De igual forma, en el campo de la educación -instrumento de política preventiva del embarazo en la adolescencia-deben perfeccionarse los programas informativos sobre la planificación familiar, la biología reproductiva y la sexualidad.

Los resultados revelan un papel importante de la familia, su funcionamiento y su supervisión del comportamiento reproductivo de las adolescentes y apuntan a que en los estudios anteriores sobre los factores determinantes de la actividad reproductiva de este grupo (inicio de las relaciones sexuales, primer embarazo) se han subestimado los factores contextuales del hogar. La erosión de la familia tradicional, patente en la sociedad occidental actual, ha contribuido a crear condiciones que favorecen la fecundidad en la adolescencia. Por tanto, constituye una meta importante para la sociedad colombiana introducir en el debate público el tema de la función que corresponde asumir a la familia frente a esta problemática.

Finalmente, los proyectos pedagógicos de educación sexual que hoy se imparten en los centros educativos del sector público y privado del país parecen no estar cumpliendo su función informativa y formativa, ya sea por insuficiencia o por defectos de enfoque. En este aspecto resulta imprescindible mejorar los servicios y programas de acceso a los métodos de planificación familiar, de un modo que resguarde la privacidad, preserve la confiabilidad y favorezca su uso apropiado entre las adolescentes. 


\section{REFERENCIAS}

1. Rodríguez J. La fecundidad alta en América Latina y el Caribe: un riesgo en transición. Documento presentado en el Seminario sobre Transición de la Fecundidad en América Latina y el Caribe. Santiago, Chile: CEPAL; 2003.

2. Flórez CE, Nuñez J. Teenage childbearing in Latin American countries. Washington, D.C.: Inter-American Development Bank; 2000. (Research Network Working paper R-434).

3. Flórez CE, Vargas E, Henao J, González C, Soto $\mathrm{V}$, et al. Fecundidad adolescente en Colombia: incidencia, tendencias y determinantes. Un enfoque de historia de vida. Santa Fe de Bogotá: Universidad de Los Andes; 2004. (Documento CEDE 2004-31).

4. Flórez CE. Los grupos de alta fecundidad en Colombia. Santiago, Chile: Centro Latinoamericano de Demografía; 1994. (LC/DEM/ R. 212. Serie A, No. 292).

5. Flórez CE. Las transformaciones sociodemográficas en Colombia durante el siglo XX. Santa Fe de Bogotá: Banco de la República, Tercer Mundo Editores; 2000.

6. Colombia, Ministerio de Educación Nacional (MEN). Proyecto nacional de educación sexual: actualización. Santa Fe de Bogotá: MEN; 1999.
7. Colombia, Ministerio de Salud. Lineamientos de políticas de salud sexual y reproductiva. Santa Fe de Bogotá: MINSA; 1998. (Documento técnico No. 1)

8. Simmons G. Research on the determinants of fertility. En: Farrooq GM, Simmons GB, eds. Fertility in developing countries. New York: Macmillan; 1985.

9. Hagestad G, Neugarten B. Age and the life course. En: Binstock RH, Shanas E, eds. Handbook of aging and the social sciences. New York: Reinhold; 1985. Pp. 35-61.

10. Bengtson V, Allen K. The life course perspective applied to families over time. En: Boss $P$, Doherty W, LaRossa R, Schumm P, Steinmetz $S$, eds. Sourcebook of family theories and methods: a contextual approach. New York: Plenum Press; 1993;469-99.

11. Davis K, Blake J. Social structure and fertility: an analytical framework. Econ Dev Cultural Change. 1956;4:211-35.

12. Moreno L, Singh S. Fertility decline and changes in proximate determinants in Latin America and the Caribbean Region. En: Guzmán JM, Singh S, Rodríguez G, Pantélides EA, eds. The fertility transition in Latin America. New York: Oxford University Press; 1996.
13. Guzmán JM, Márquez R, Contreras JM. Diagnóstico sobre salud reproductiva de jóvenes y adolescentes en América Latina y el Caribe. Documento presentado en la Reunión de Planeación Regional en Población. México, D.F.: Fondo de Población de las Naciones Unidas; 2000.

14. Cox DR. Regression models and life tables. J Royal Stat Soc. 1972; Series B 34:187-202.

15. Vargas E, Henao J, González C. Fecundidad adolescente en Colombia: incidencia, tendencias y determinantes: un enfoque de historia de vida (informe final del estudio cualitativo). Santa Fe de Bogotá: Universidad de Los Andes; 2004.

16. Ruhm C. Maternal employment and adolescent development. National Bureau of Economic Research (NBER). Cambridge (Ma): 2004. (Working paper 10691).

Manuscrito recibido el 21 de diciembre de 2004. Aceptado para publicación, tras revisión, el 13 de septiembre de 2005.
ABSTRACT

Socioeconomic and contextual determinants of reproductive activity among adolescent women in Colombia

Key words
Objective. To contribute to a better understanding of the problems of pregnancy among adolescent women, including proximate and socioeconomic determining factors, in two large, culturally different cities in Colombia: Santa Fe de Bogotá and Cali. Methods. This longitudinal study combined quantitative and qualitative research methods, using information generated by a survey of adolescents conducted in 2003. The survey included 550 adolescents in Bogotá and 550 adolescents in Cali, from all socioeconomic strata. To analyze the determinants, discrete-time proportional hazards models were used. For the qualitative study, 72 in-depth interviews and four focus groups were done. With the information organized by subjects and categories that were defined in relation to the purposes of the study, categories were identified that arose from the patterns and recurrences in the data, in order to see sociocultural trends by sex, stratum, and city.

Results. The patterns of sexual activity, union (married or unmarried relationship), and maternity differ considerably among the socioeconomic strata, in both of the cities. The adolescent women in the low stratum begin having sexual relations, form unions, and become mothers earlier in life and with greater frequency than do adolescent women in the medium or high strata. The main determinant of the reproductive behavior of adolescent women is the set of contextual and socioeconomic factors in the home, mainly the family context (environment and supervision) and the educational climate (the average number of years of formal education of the family members over the age of 15$)$.

Conclusions. Sex education has been provided in the schools in Colombia since 1993, but our results clearly indicate that it has had only a limited impact on the reproductive behavior of adolescent women. 